\title{
Preventing landslides in times of rainfall: case study and FEM analyses
}

\begin{abstract}
Purpose: The purpose of the paper is to present a new method of controlling through susceptible slopes in order to reduce the risk of landslides.

Design/methodology/approach: Geotechnical and geological characteristics were collected and different FEM analyses were carried out in a case study of the Alasht valley in Northern Iran in order to determine susceptibility to landslides and consider appropriate countermeasures. Gravel drain piles have a real feel of reducing the pore water pressure in times of seismic loading, so they are used as a remediation method. The results clearly show their effects and an increase in safety as a result.

Findings: Since the water table situation has a significant effect on stability, the present study focused on an example of using a seepage controlling system and its effect on the safety factor for different slopes in the area of Alasht, Northern Iran. Several FEM analyses were carried out on a landslide susceptible case. The results from FEM analysis of different slopes in the study area show a high susceptibility to landslides for six sites. Installing a gravel drain pile surrounded by a non-woven geotextile layer leads to an increase in the safety factor against landslides. As a result, after installing gravel drain piles in the upper parts of slopes in order to control run out and ground water rising up in times of heavy rainfall, the safety factor against landslides in both static and seismic loading improved significantly.

Originality/value: The literature regarding controlling seepage in order to reduce the risk of landslides is limited. This paper collects and analyses geotechnical and geological data from the Alasht valley as an example to show the high risk of susceptibility to landslides.
\end{abstract}

Keyword: Case studies; Iran; Landslides; Modelling 